\title{
OS PARADOXOS DA FORMA ESCOLAR NA CONTEMPORANEIDADE
}

THE PARADOXES OF SCHOOL FORM IN CONTEMPORANEITY

LAS PARADOJAS DE LA FORMA ESCUELA EN LA CONTEMPORANEIDAD

SARAIVA, Karla

AQUINO, Julio Groppa

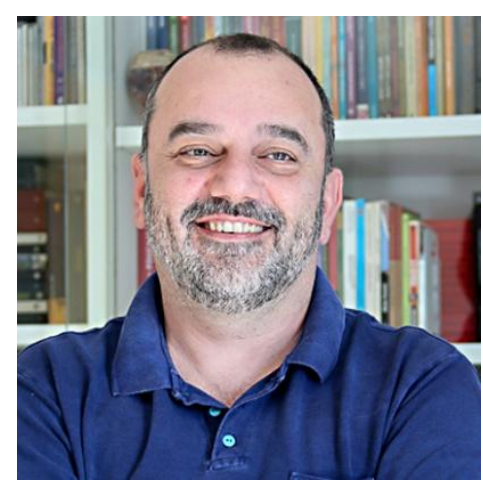

Julio Groppa Aquino é, sem dúvida, um dos mais proeminentes pesquisadores do campo educacional da atualidade. Professor titular da Faculdade de Educação da Universidade de São Paulo (USP), é graduado em Psicologia, mestre e doutor em Psicologia Escolar. Tem, ainda, pós-doutorado pela Universidade de Barcelona e livre-docência pela Faculdade de Educação da USP. É pesquisador do CNPq nível 1D e lidera o Coletivo de Pesquisadores sobre Educação e Relações de Poder (COPERP-USP), grupo cadastrado no CNPq. Integra a Red de Educación y Pensamiento Contemporáneo (RIEPCO), grupo de pesquisadores latino-americanos, bem como a Rede de Pesquisa Escrileituras da Diferença em Filosofia-Educação. Vem desenvolvendo investigações voltadas ao encontro do pensamento foucaultiano com a educação brasileira, bem como aos processos de governamentalização em curso na atualidade educacional. Foi responsável pela orientação de 26 dissertações de mestrado, 14 teses de doutorado e nove trabalhos de pós-doutorado, todos já concluídos.

É autor, coautor e organizador de um conjunto de artigos, livros e capítulos, com vistas a uma crítica sistemática das práticas educacionais correntes, tanto em sua versão formal quanto na não formal. Sua obra se destaca não apenas pela extensa lista de publicações, mas, principalmente, pela sua qualidade. Com uma escrita elegante e sofisticada, vem discutindo temas centrais para compreender o presente e para pensar de outros modos a Educação na atualidade. Sua abordagem nunca é trivial, colocando sob tensão verdades consolidadas. Sua produção acadêmica é composta atualmente por 68 artigos, 32 deles publicados nos últimos cinco anos, e 42 capítulos de livro, sendo 
algumas destas produções com coautoria. Também foi responsável pela publicação de 33 livros, sendo sete deles de autoria exclusiva. Recebeu o prêmio Jabuti, categoria educação/pedagogia, em 2015, com o livro Da autoridade pedagógica à amizade intelectual. uma plataforma para o éthos docente. Em 2019, foi publicada uma reunião de 30 textos seus - de periódicos, livros e jornais - intitulada Educação pelo arquivo: ensinar, pesquisar, escrever com Foucault, que dá acesso a grande parte de sua produção individual da última década.

Porém, para além de sua produção acadêmica, também se dedica a divulgar suas ideias em espaços voltados para um público mais amplo, como jornais e revistas comerciais. São mais de 150 artigos e entrevistas em veículos como Folha de São Paulo, Estadão, entre outros. Durante um período, foi colunista das revistas Nova Escola e Educação. Este conjunto de publicações, desenvolvido entre 1994 e 2019, forma um mosaico que permite conhecer um pensador inquieto e profícuo. Na entrevista que segue, estabelecemos um diálogo que permite avançar na problematização das práticas educacionais nos turbulentos tempos contemporâneos.

Karla Saraiva: De acordo com diversos pesquisadores, dentre os quais ocupas lugar de destaque, a educação desempenha papel fundamental para o funcionamento contemporâneo da governamentalidade, entendida como a forma privilegiada de governo de si e dos outros. E é exatamente neste contexto que se consolida o conceito de sociedade de aprendizagem ou, de acordo com Ball (2013), que se constitui uma sociedade totalmente pedagogizada. Neste tipo de sociedade, a educação tende a ocupar parcelas crescentes da vida, tornando-se não apenas uma aprendizagem ao longo da vida, como também invadindo cada vez mais o cotidiano. Estaríamos vivendo um processo de educacionalização que espraia os processos de aprendizagem por diversas práticas que não estão limitadas à educação formal. Propalar o caráter pedagógico de um produto ou serviço é algo que agrega valor, seja voltado para o público infantil ou adulto. Reportagens da mídia impressa e da TV, livros (com destaque para o profícuo campo da literatura de autoajuda), filmes, videoaulas dos mais diversos temas são alguns dos recursos que utilizamos para aprender em períodos que deveriam ser de ócio. A aprendizagem é importante para o trabalho e também se torna uma forma de lazer. Aprender vem se tornando um hábito naturalizado, escolarizando a sociedade, como bem apontas no artigo Two premises and one general hypothesis for the analysis of the educational present (AQUINO, 2017b). Entretanto, parece-me que, ao atribuirmos um valor que eu diria excessivo à aprendizagem, paradoxalmente nos distanciamos da possibilidade de uma estilização da vida. A aprendizagem que estes artefatos oferecem seria, na imensa maioria das vezes, prescritiva e normalizadora, proporcionando experiências que nos enclausuram e fragilizam a relação com o outro, que fixam as identidades e engessam as subjetividades. Estariam mais próximos a uma esterilização da existência do que de um cultivo de si. Neste cenário, seriam possíveis práticas educativas que pudessem contrariar esta lógica e que funcionassem como técnicas para o cultivo de si e para a estilização da existência? E essas práticas poderiam se estender para a população em geral ou acabariam por estar restritas a uma camada privilegiada, como se dava entre os gregos? 
Julio Groppa Aquino: Quando se vislumbram os efeitos das práticas educacionais no mundo atual, não é possível, a meu ver, se ater ao âmbito escolar stricto sensu. É preciso que haja uma mirada dupla para os vetores centrípetos e centrífugos que caracterizam os fazeres educacionais. Além do texto por você citado (AQUINO, 2017b), dediquei outro escrito a essa mesma questão, o qual me parece fazer sentido ainda (AQUINO, 2012). Lá, a hipótese principal é a de que haveria dois movimentos, à primeira vista, antagônicos, mas em perfeita consonância, presidindo o que pensamos e fazemos na educação hoje. De um lado, a disjunção - advinda do choque entre as demandas superavitárias atribuídas à instituição escolar e a resposta fragmentária e, no mais das vezes, insuficiente da parte dos seus profissionais, redundando na crescente percepção de saturação das ações ali em curso. De outro lado, a dispersão - entendida como efeito do espraiamento, sem precedentes, de iniciativas portadoras de intencionalidades pedagógicas para além do escopo escolar, as quais parecem contar com uma espécie de otimismo exacerbado quanto à própria eficácia. Daí a noção de pedagogização ou, como preferem alguns autores, de educacionalização social: fenômeno que não poderia ser compreendido sem sua contraparte escolar. O que distingue os dois movimentos, claro está, é o solapamento da ideia de ensino (no caso da disjunção), em oposição complementar ao triunfo da noção de aprendizagem (no caso da dispersão).

No que diz respeito à sua primeira questão, torna-se difícil imaginar práticas capazes de fazer frente ao imperativo férreo da aprendizagem autogerida. Para desnaturalizar tal lógica, seria necessário refundar, de algum modo, a noção de formação entendida em seu sentido lato, o que requer um esforço de discriminação e, portanto, de imaginação recriadora em face da avalanche informativa que assola a vida contemporânea. $E$ isso um professor poderá oportunizar se for capaz de se postar como um anteparo - um filtro ético-estético, talvez - entre o que nos obrigam a conhecer e o que poderíamos vir a pensar por conta própria. A formação de qualquer um, nesse sentido, orienta-se mais por formas abertas de pensamento e menos por um repertório estável de conhecimentos válidos, úteis etc. $E$ tal abertura só é possível por meio de uma imersão indeterminada, sem reverência de nenhuma ordem, nas formas pregressas de inteligibilidade do mundo legadas por nossos antepassados; imersão viabilizada, queríamos ou não, apenas por um professor cônscio de seus afazeres. Grosso modo, é isso que entendo por formação.

Quanto à segunda pergunta, há um problema lógico-político quando delimitamos o mundo em termos de alguns versus muitos. Disso decorre que não se trata de imaginar espaços privilegiados para o que acabei de formular. Bem ao contrário. Essa efervescência ético-estética pode ocorrer em quaisquer quadrantes; ela só dependerá da intensidade variável dos encontros. Para tanto, é mais o tipo de fibra existencial e, sobretudo, o compromisso público de um professor que dão o tom desse modo de relação consigo e com os outros, e menos o contexto $x$ ou y. Este é, no limite, um complicador, não um condicionante da ação docente.

Karla Saraiva: Ao olharmos para o conjunto de discursos contemporâneos sobre a educação escolar, é possivel identificar que um dos enunciados de maior destaque refere-se ao protagonismo do aluno e à importância de seu envolvimento ativo no processo de aprendizagem. Associado a isso, estão sendo 
naturalizadas afirmações de que a escola deve atender os interesses dos alunos, deve utilizar metodologias de ensino e percursos que contemplem as individualidades, deve realizar atividades conectadas como o "mundo real" ou com a comunidade. Masschelein e Simons (2013), na obra Em defesa da escola, posicionam-se na contramão desses discursos, afirmando que a escola deve fornecer tempo livre, ou seja, tempo não produtivo, para proporcionar formação. A formação está além da aprendizagem, que pode acontecer em vários outros momentos. Ela não se relaciona com atender necessidades individuais, mas com apresentar o mundo aos alunos para que eles possam nele se inserir e o transformar. Os autores chegam a afirmar que existiria uma desescolarização da escola. Articulando as problematizações destes autores com as que trazes no artigo anteriormente mencionado, é possível pensar que haveria uma escolarização das sociedades em conjunto com uma desescolarização da escola? Qual poderia/deveria ser a função específica da escola na sociedade de aprendizagem?

Julio Groppa Aquino: Tive a oportunidade de organizar, junto com um colega, um dossiê para a revista Educação Temática Digital, intitulado É preciso defender a escola (CARVALHO; AQUINO, 2017), a reboque do livro do Masschelein e do Simons (2013). A publicação deste livro foi um alento para aqueles que vêm tentando franquear alguma sobriedade ante os ditames do discurso pedagógico centrado nos processos de aprendizagem. Aliás, curiosamente, há um livro meu com o mesmo título, escrito em parceria com outra colega, sob o título Em defesa da escola (SAYÃO; AQUINO, 2004). Uma década os separa, mas há várias similaridades em ambos, sobretudo a defesa da causa escolar.

Advogar em favor da escola significa, entre outros compromissos, manter uma distância estratégica tanto da louvação dos interesses discentes - estes, sempre imediatos, por sinal - quanto da mimetização escolar de um dito mundo real, a título de uma maior resolutividade pedagógica. Inclua-se o bordão que prega o incremento da atratividade das ações pedagógicas, já que não se trata de um labor associado à obtenção de prazer; se este existe - e pode perfeitamente existir - será à custa de esforço por parte de ambos, alunos e professores. E esforço, aqui, significa não o usufruto de um suposto protagonismo individual, mas uma diferenciação ética de si mesmo, ou seja, aquilo que chamei antes de formação.

Eis a medida que caracteriza a ação escolar de fato: o quanto ela é capaz de desencadear transformações substantivas nos modos de pensar e de se conduzir; o que vale, repito, tanto para os alunos quanto para os professores. Sem isso claramente delineado, as salas de aula convertem-se em lugares de passagem apenas, e a relação entre seus protagonistas, em fetiche comunicacional.

Desta feita, reputo a experiência escolar, aquém ou além da tal sociedade de aprendizagem, como um arranjo social que, antes de arregimentar o que deveríamos conhecer a fim de garantir um lugar ao sol, nos permite duvidar do que já sabemos e, com isso, assegurar novos horizontes existenciais sob esse mesmo sol. É precisamente o trabalho infinito da liberdade de pensar que está em causa aí - e na berlinda, tudo leva a crer.

Karla Saraiva: Neste contexto, os professores vêm sendo chamados de facilitadores da aprendizagem, animadores da inteligência coletiva, gestores do desenvolvimento de competências, entre outras 
expressões que se pode encontrar na literatura educacional. Parece-me que se forja uma identidade docente que destitui o professor de um lugar de saber, realocando-o em uma posição próxima a de um gestor (como fica explícita na última denominação apresentada). Estes novos modos de identificar os docentes não implicariam uma desvalorização profissional? Além disso, este deslocamento no modo de significar a docência não poderia estar, de algum modo, implicado com a crescente violência nas escolas, uma vez que os professores estariam perdendo a autoridade e o reconhecimento que eram conferidos, justamente, por ocuparem um lugar de saber?

Julio Groppa Aquino: Os dois efeitos colaterais das transfigurações da docência nas últimas décadas, que você bem aponta, são notórios: de um lado, a fragilização da imagem social do professorado e, com isso, sua desvalorização não apenas profissional, mas também política; de outro, a crescente clientelização do alunado, redundando em tédio ou, no limite, violência. Se, por um lado, é possível admitir que nada há de errado com o que se passa nas escolas, uma vez que se trata do alcance possível de nossas aspirações, por outro, é possível admitir também que estamos diante de uma espécie de esgotamento da forma escolar, tal como ela vem sendo concebida e praticada na batuta do neoliberalismo.

Tal esgotamento, correlato à hipótese de desescolarização da escola dos autores belgas, toma corpo em alguns expedientes pedagógicos que emulam o universo empresarial (no caso da escola privada) ou o terceiro setor (no caso da pública). As escolas, nesse sentido, não apenas reproduzem os comandos da época, mas também se antecipam a eles, testando seus limites e aprimorando suas formas de atualização. Trata-se, é verdade, da face sombria da instituição. Entretanto, como prática viva que é, a escolarização comporta toda sorte de contra efeitos. É exatamente nisso que reside sua força política, creio. E ela é, nesse caso, da ordem da exceção.

Seria preciso, portanto, perspectivar o raio de ação escolar hoje em termos de uma agonística ininterrupta. Ou seja, se, por um lado, as práticas escolares amiúde enrodilham-se facilmente nos usos instrumentais da razão comunicacional, secundados pela livre expressão opinativa do alunado, por outro, nunca tivemos uma chance tão ampla de contar com o envolvimento dos alunos e, com isso, alterar - ou ao menos confundir - as regras dos jogos cognitivos em voga. Novamente, desponta a potência intransferível de um professor cônscio de seu ofício. A força de sua presença é a única bala na agulha de que dispõe. Há de arriscar o tiro. $\mathrm{E}$, se a isso se dispuser, que o faça à moda do arqueiro zen, ou seja, aquele que acerta o alvo sem ter feito pontaria (HERRIGEL, 2007).

Karla Saraiva: De acordo com Lagasnerie (2013), em seu livro A última lição de Foucault, o filósofo francês teria vislumbrado a possibilidade de fazer do neoliberalismo uma ferramenta de crítica. Sem colocar-se como defensor ou opositor a esta doutrina econômico-política, ele teria enfatizado a importância da defesa que ela faria da diversidade e da preservação das liberdades individuais para a escolha dos modos de ser e de viver, contrapondo-se a um Estado regulamentador, para a construção de uma filosofia de resistência política. No contexto educacional que se desenha no Brasil de 2016, observamos o fortalecimento do Movimento Escola sem Partido. Suas ideias já estão orientando 
projetos de lei, tanto em níveis estaduais, quanto nacional. $\mathrm{O}$ tema tem sido presença constante na mídia e o atual ministro da Educação, Ricardo Vélez, já expressou sua simpatia pela ideia. No momento, tramita no Senado um PL de autoria do Senador Magno Malta, pastor de uma igreja neopentecostal, que cria o Programa Escola sem Partido. Este PL, submetido a consulta pública, foi motivo de intensa mobilização popular, recebendo mais de 350.000 votos, com leve vantagem daqueles que se colocam de forma contrária. O programa prega a "neutralidade política, ideológica e religiosa", defende o "direito dos pais a que seus filhos recebam a educação religiosa e moral que esteja de acordo com as suas próprias convicções" e destaca que está "vedada, especialmente, a aplicação dos postulados da teoria ou ideologia de gênero". Por outro lado, embora não esteja explícito no PL, o Movimento Escola sem Partido opõe-se frontal e ferrenhamente a tudo que possa parecer um pensamento de esquerda (frequentemente reduzido ao que chamam de ideologia marxista ou comunista). Neste sentido, parece-me que o Escola sem Partido se caracteriza por um amálgama que vem se consolidando na sociedade brasileira nos últimos tempos que articula uma orientação econômica neoliberal com um conservadorismo social relacionado com o pensamento neopentecostal que vem ganhando espaço não apenas pela conquista crescente de fiéis, como também pela naturalização de suas concepções moralistas e cerceadoras das individualidades na sociedade de modo mais amplo. Ou, dito de outro modo, se aceitarmos as problematizações de Lagasnerie (2013), teríamos um neoliberalismo do qual foi subtraído justamente aquilo que Foucault teria vislumbrado como sua potência, retendo-se apenas seus aspectos mais sombrios. Contudo, em 2016 também assistimos a uma série de movimentos estudantis pelo Brasil de ocupação das escolas, reivindicando seus direitos por uma educação de qualidade e defendendo a diversidade. Como percebes estes movimentos em torno da escola e que efeitos eles poderão ter para os processos de escolarização nos próximos anos?

Julio Groppa Aquino: Parto do pressuposto de que a escola não consiste apenas em uma caixa de ressonância da história sociopolítica do país; ela é uma protagonista-chave dessa mesma história. Nessa direção, a conjuntura educacional brasileira, é fato, tem sido alvo de pressões contraditórias, malgrado consistam em duas faces de uma mesma moeda, por assim dizer. Por exemplo, a defesa de uma escola inclusiva e de qualidade é uma invariante no discurso político-pedagógico, de ponta a ponta, incluindo seus porta-vozes mais conservadores. Certamente, a ideia de qualidade implica uma gama de características que podem, inclusive, ser opostas, a depender dos reclamos dos diferentes grupos de interesse.

Assim, os dois movimentos que você menciona parecem ser exemplos vivos da dramaturgia sociopolítica que o país vem encarnando nas últimas décadas, seja na versão inclusivo-assistencial do governo anterior, seja na versão tecnocrático-empresarial do governo atual. O que ambas as forças têm em comum é o apego a determinados valores em torno de certa noção de liberdade como usufruto individual dos cidadãos, sem a qual o presente democrático não parece se reconhecer em pleno funcionamento. 
Daí a constatação de que, ao mesmo tempo em que há um pleito conservador de determinados setores sociais com vistas a uma tal neutralidade ideológica do ensino, cresce a reivindicação, por parte de outros setores, do respeito às diferenças humanas, sociais, culturais etc. da população escolar. Tempos confusos estes, sem dúvida, em que a centralidade de uma política voltada a um horizonte comum parece estar arrefecendo em favor de embates regionalizados, os quais compreendem, por exemplo, ora clamores sexistas, ora direitos identitários, ora uma terceira onda que nunca sabemos quando arrebentará.

Essa coexistência tensa de valores em disputa parece ser o saldo e, ao mesmo tempo, a própria espinha dorsal do neoliberalismo na atualidade, o qual opera fundamentalmente por meio do primado da gestão de crise. Isso significa que, ao mesmo tempo em que o neoliberalismo oferece uma via de crítica aos excessos estatais, ele fomenta um desencaixe constante das relações sociais, com vistas à geração de demandas sempre novas e, por isso, jamais plenamente equacionáveis. Em suma, a crise desponta não apenas como o modus operandineoliberal, mas também como seu leitmotiv.

$\mathrm{Na}$ tentativa de esboçar uma resposta à sua questão, intuo que os enfrentamentos em torno da escolarização tenderão a se multiplicar, em diferentes e conflitantes direções. Estamos assistindo, parece-me, ao nascimento de uma nova forma de contratualização social entre as instituições e os cidadãos, a qual abarcará não apenas a customização dos processos de aprendizagem, mas, sobretudo, a judicialização das relações escolares - seja à direita, seja à esquerda, aliás. Daí as práticas do direito como reguladoras do mundo em sua versão democrático-neoliberal, inclusive no quadrante educacional.

Karla Saraiva: Ainda de acordo com Foucault (2008), o neoliberalismo governa por meio da liberdade. É um sistema produtor e consumidor de liberdade, um governo sutil, que tira sua eficácia de sua invisibilidade. Se estivermos de acordo com as problematizações de Foucault (2019), deveríamos poder dizer que queremos ser governados "não dessa forma, não para isso, não por eles". No campo educacional, preconizam-se metodologias de ensino cada vez menos coercitivas, que promovem a condução das condutas suavemente, incentivando os alunos a agirem em prol de seus interesses e de suas escolhas. Ou, dito de outro modo, metodologias que jogam com a liberdade. Neste sentido, seria possível afirmar que a escola contribui para esta dificuldade de identificar o modo como somos governados, reafirmando uma sujeição não refletida. Talvez seja necessário "libertar a liberdade", como já afirmou Jorge Larrosa (2000), e, para isso, talvez seja necessário, de modo um pouco paradoxal, inventarmos outras metodologias de ensino mais diretivas que permitiriam aos alunos outra relação com as formas com que são governados. Seria possível pensar uma escola orientada para reflexões sobre o modo como somos governados?

Julio Groppa Aquino: Além de subscrever integralmente sua visão do problema do encontro da educação com certa noção privatista de liberdade, gostaria de retomar um aspecto subjacente a este diálogo nosso: o lugar teórico do qual ambos falamos. Obviamente, estamos posicionados no campo 
dos estudos foucaultianos na educação e, portanto, atentos a um tipo de discussão que reserva para si uma espécie de suspensão tática em relação ao mainstream discursivo do campo, este quase sempre obstinado com o incremento da produtividade pedagógica e, em particular, com a otimização ad infinitum dos processos de aprendizagem.

Nesse diapasão, o trabalho do pensamento circunscreve-se à interpelação dos excessos das práticas, e não ao fomento de novos limiares dessas práticas em substituição ou em apoio àquelas já existentes. Com isso, abdicamos da fantasia de que haveria ações educativas mais profícuas, mais urgentes etc. Aliás, julgo que este é o papel da teorização educacional como um todo: recusar toda espécie de voluntarismo pedagogizante, atendo-se ao esquadrinhamento crítico da racionalidade imanente a tudo aquilo que já fazemos em nome da educação dos outros, seja dentro, seja fora das escolas.

Outro ponto-chave remete ao próprio corpo discursivo, hoje, do campo foucaultiano na educação. Grande parte das críticas de outras frentes teóricas às produções de timbre foucaultiano diz respeito a um suposto caráter inercial - quando não, entreguista - das ideias aí presentes. Ora, é preciso relembrar o fato de que, historicamente, as primeiras apropriações do legado foucaultiano na educação ainda em meados dos anos 1990, embaladas pelo espírito contestatório no Brasil à época, prestaramse a denunciar o lastro disciplinar dos fazeres escolares de então. Vigiar e punir tornou-se, assim, uma espécie de manual da discórdia pedagógica. Passadas mais de duas décadas, o cenário mudou consideravelmente. Com o advento dos cursos ministrados no Collège de France - a meu ver, a fonte mais consistente das ideias foucaultianas a partir de 1970 -, novos problemas teóricos e, sobretudo, procedimentais foram somados ao debate, com destaque para as noções articuladas de biopolítica e governamentalidade. Mais recentemente, a partir da publicação tardia dos últimos cursos ministrados entre 1979 e 1984, outras elaborações ainda mais intrincadas têm vindo à tona. O que avulta entre esses diferentes Foucaults, por assim dizer, é a guinada da tópica poder versus resistência para a do governo via liberdade. Também a questão da verdade ganha outro estatuto analítico, ainda mais pregnante, doravante situada em termos de jogos de veridicção associados aos processos de subjetivação - com vistas a uma ontologia crítica do presente capaz de abdicar da ideia de história seja como avanço, seja como degradação, seja ainda como um movimento pendular entre ambos. O presente é enigma, e nada mais.

Apenas tendo tal horizonte em vista, creio, torna-se possível enveredar pelo presente educacional com certa mesura e, ao mesmo tempo, com algum vagar, desprovido de qualquer gana denuncista. Desse modo, abstenho-me por completo de imaginar cenários outros para as práticas educativas como um todo. Ou seja, prefiro ser apenas um espectador atento - algo rodrigueano, por assim dizer. Um espectador aflito, é bem verdade, mas apenas um espectador.

E, como tal, cultivo uma desconfiança básica em relação a qualquer formulação salvacionista, seja no sentido de uma refração aguerrida, seja no de adesão moderada aos ditames neoliberais em voga. No entanto, preservo certa expectativa de que as crianças e os jovens serão fortes o bastante para aguentar o tranco que lhes aguarda e, em alguma medida, para oferecer uma resposta imprevista a isso. Se eficaz ou não, só o futuro dirá.

E já que alinhados ao pensamento foucaultiano carecemos de um salvo-conduto de véspera, resta-nos apenas uma interpelação radical do que somos, fazemos e pensamos nas escolas - e além delas, 
claro. Eis o divisor de águas de tudo o que porventura formos capazes de fazer de nós mesmos. Parece pouco, mas é tudo de que dispomos, de fato.

Karla Saraiva: Finalizando, sinteticamente, qual seria o objetivo da escola no mundo contemporâneo e como ela poderia ser organizada para atingi-lo?

Julio Groppa Aquino: Retomando sua hipótese inicial sobre o dilema esterilização versus estilização da vida, acabo imaginando que, seja no âmbito da prática docente, seja no da reflexão sobre educação, precisamos expressamente de extravagâncias. As práticas pedagógicas, convenhamos, são demasiado enfadonhas quando elas perdem seu caráter laboratorial, quando os processos éticoestéticos ali sediados não mais encontram vazão e talhe.

Onde foram parar aqueles professores excêntricos que, paradoxalmente, habitavam a antiga escola disciplinar? Sem passadismo de nenhuma ordem, julgo que, frente à anódina ladainha das pedagogias contemporâneas, seria plenamente possível que os alunos testemunhassem uma ambiência cadenciada por alguns expedientes típicos da escola dita tradicional.

Nenhum problema, portanto, que a voz docente seja axial nas trocas discursivas, e que os alunos possam exercitar algum silêncio e, sobretudo, experimentar a arte da escuta. $E$ isso só pode se efetivar quando os mais velhos se dispõem, sem nenhuma reserva, a deslindar nosso mundo comum como um grande arquivo, e, ao fazê-lo, possibilitar sua reconstrução paulatina; reconstrução que será lograda apenas pelos mais novos, desde que nos disponhamos a ensiná-los a fazê-lo.

Soma-se a isso o fato de que o trabalho de estilização de uma vida é uma prerrogativa e, ao mesmo tempo, um dever inarredável de todo aquele que se dispõe a levar sua vida entre as novas gerações. Ter apreço por estas significa oferecer-lhes a oportunidade de se mestiçarem com aquilo que desconhecem e que, não obstante, Ihes pertenceu desde sempre. Que o mundo dos mortos das obras, pela boca de um professor, possa, então, se amalgamar pouco a pouco ao mundo dos vivos das aulas. Uma educação pelo arquivo, em suma. Trata-se daquilo que, em outra ocasião, tentei formular com a noção de amizade intelectual.

Para que a vida se mantenha em movimento - não importa em qual direção - cumpriria aos contemporâneos uma atitude nem de rechaço, nem de submissão contemplativa da matéria constituída, não obstante fragmentária, turva e indócil, que chega até nós, mas, exatamente, a escolha de preservá-la viva por intermédio de sua permanente reconstituição. Tratar-se-ia, portanto, de reinserir tal matéria no jogo ininterrupto e instável do tempo, a fim de que ela não fosse condenada à elisão do esquecimento. Em suma: caber-nos-ia deixar para os que virão aquilo que, não obstante inteiramente reconstituído por nós, já nos havia sido deixado pelos que se foram. (AQUINO, 2014, p. 185).

Agradeço muito a oportunidade do diálogo. 


\section{REFERÊNCIAS}

1. AQUINO, Julio Groppa. Disjunção, dispersão e dissensão da educação contemporânea. In: SARAIVA, Karla; MARCELLO, Fabiana A. (Orgs.). Estudos culturais e educação: desafios atuais. Canoas: ULBRA, 2012. p.137-158.

2. AQUINO, Julio Groppa. Da autoridade pedagógica à amizade intelectual: uma plataforma para o éthos docente. São Paulo: Cortez, 2014.

3. AQUINO, Julio Groppa. Defender a escola das pedagogias contemporâneas. Educação Temática Digital, Campinas, v. 19, n. 4, p. 669-690, out./dez. 2017a.

4. AQUINO, Julio Groppa. Two premises and one general hypothesis for the analysis of the educational present. Educational Philosophy and Theory, v. 49, p. 672-680, 2017b.

5. BALL, Stephen. Aprendizagem ao longo da vida, subjetividade e a sociedade totalmente pedagogizada. Educação (Porto Alegre), v. 36, n. 2, p. 144-155, maio/ago. 2013.

6. CARVALHO, Alexandre Filordi de; AQUINO; Julio Groppa. ETD - Educação Temática Digital, Campinas, v. 19, n. 4, p. 585-589, out./dez. 2017.

7. FOUCAULT, Michel. Nascimento da biopolítica. São Paulo: Martins Fontes, 2008.

8. FOUCAULT, Michel. O que é a crítica? [Crítica e Aufklärung]. Disponível em http://michelfoucault.weebly.com/uploads/1/3/2/1/13213792/critica.pdf. Acesso em 22 jul. 2019.

9. HERRIGEL, Eugen. Zen e a arte do tiro com arco. Lisboa: Biblioteca Editores Independentes, 2007.

LAGASNERIE, Geoffroy de. A última lição de Michel Foucault. São Paulo: Três estrelas, 2013.

11. LARROSA, Jorge. A libertação da liberdade. In: PORTOCARRERO, Vera; CASTELO BRANCO, Guilherme. (Orgs.). Retratos de Foucault. Rio de Janeiro: Nau, 2000. p. 328-335.

12. MASSCHELEIN, Jan; SIMONS, Maarten. Em defesa da escola: uma questão pública. Belo Horizonte: Autêntica, 2013.

13. SAYÃO, Rosely; AQUINO, Julio Groppa. Em defesa da escola. Campinas: Papirus, 2004 


\section{Karla Saraiva}

Doutora em educação.

\section{Julio Groppa Aquino}

Doutor em educação.

\section{Como citar este documento:}

SARAIVA, Karla; AQUINO, Julio Groppa. Os paradoxos da forma escolar na Contemporaneidade. Reflexão e Ação, Santa Cruz do Sul, v. 28, n. 2, jun. 2020. ISSN 1982-9949. Disponível em: <https://online.unisc.br/seer/index.php/reflex/article/view/14499>. Acesso em: doi:https://doi.org/10.17058/rea.v28i2.14499. 